\title{
OBSERVATIONS ON DYSENTERY IN CHILDREN
}

\author{
BY \\ DAVID NABARRO, M.D., F.R.C.P., \\ and \\ A. GORION SIGNY, M.B., B.S.
}

(From the Hospital for Sick Children, Great Ormond Street, London.)

For more than 20 years one of us (D. N.) has been interested in the subject of bacterial dysentery in this country, and many years ago came to the conclusion that the disease was much more prevalent among children than was generally realized. As far back as 1914, in a short paper written in conjunction with A. Distaso ${ }^{1}$, it was shown that in 19 cases of enteritis and colitis and 2 of cœliac disease, all in children, a probable dysenteric infection could be demonstrated by the isolation of a Flexner-type dysentery bacillus from the fæces in 5 cases, and by the agglutination power of the patient's serum in all the cases. The Sonne bacillus was not identified as we were unacquainted with it at that time.

The relation of the dysentery bacilli to the zymotic enteritis or epidemic diarrhœa of infants is an interesting problem which is still in part unsolved. In 1902, Duval and Bassett ${ }^{2}$ isolated dysentery bacilli from 42 out of 53 cases of infantile diarrhœa, and they concluded that the dysentery bacillus ' is an important, if not the most important, cause of summer diarrhœa in children.' In 1903, the Rockefeller Institute undertook a comprehensive investigation in several American cities on the occurrence of the dysentery bacillus in the summer diarrhœa and other diarrhœal diseases of children. Dysentery bacilli were isolated in 63.2 per cent. of the 412 cases investigated; they were mainly of the Flexner type, but the Shiga bacillus was also met and occasionally the two types were associated. Flexner ${ }^{2}$, who had charge of the investigations, in his conclusions stated ' that it is probable, though not proven, that the B. dysenteriæ appears at times among the saprophytic bacteria of the intestinal contents.'

Since 1913 a number of cases of dysentery have been recognized every year in this hospital, but owing to the fact that prior to 1912 no systematic investigation for dysentery bacilli in the fæces was carried out, it is impossible to say if the numbers have increased since the war.

In the diarrhœa epidemic of 1921 when 111 cases of summer diarrhœa were admitted to the Hospital for Sick Children, Great Ormond Street, bacteriological investigations were carried out by one of us (D. N.) in 
co-operation with D. Paterson ${ }^{3}$ upon 68 of these cases. Dysentery bacilli of the Flexner and Sonne types were isolated in 27 out of the 68 cases studied $\left(39 \cdot 7\right.$ per cent.), and in 11 out of a further $39^{6}$ sporadic' cases of diarrhœa in children and nurses. The Sonne bacillus was not recognized as such at the time, but the organism isolated was called the B. coli anærogenes ${ }^{3}$.

\section{Present investigations.}

The subject matter of the present paper is based on all the cases of dysentery which occurred in the hospital during 1929, 1930, 1931, and the first 11 months of 1932. Most of the cases, it will be shown, occurred in small ward cutbreaks, and it will be seen that the number of established cases, i.e., bacteriologically proven, is far greater than would be expected from current opinion as to the prevalence of the disease in this country. Dysentery in England is regarded as a rare disease outside mental hospitals, and acute attacks of diarrhnea in children are labelled gastro-enteritis or ileo-colitis, often without any attempt being made to establish a bacteriological diagnosis.

Bacteriology.-Routine examination. It is now a routine of this hospital that every case of diarrhoea admitted to the wards, or arising during a stay in hospital, is immediately placed under infectious precautions and a stool sent for bacteriological investigation. Whether the result is positive or negative, the child is only removed from these precautions when the stool shows no abnormal micro-organisms on at least three consecutive days. Routine stool examinations consist of careful macroscopic and microscopic search for blood and pus, and of cultural investigations. The latter are made straight from an emulsion of the fæces, preferably using a portion containing mucus, on two McConkey plates, and after 24 hours' incubation every type of non-lactose fermenting colony is further investigated. The number of non-lactose fermenting colonies which are isolated from an acute dysenteric stool varies enormously, from one or two colonies per plate to pure growths. The diagnosis of the type of micro-organism is determined and controlled by the following two methods:-

By direct agglutination:-Rabbit serum of high agglutinating titre is prepared by 3 or 4 weekly intravenous injections of formalized broth cultures of the ccmmonest strains (Flexner V, W, X, Y, Z and Sonne). The sera are then ' absorbed' with all the other strairs to remove the co-agglutinins, and are used at $1 / 10$ or $1 / 20$ dilution for rapid diagnosis. One drop of each serum is placed on a clear slide, and mixed with a small part of the non-lactose-fermenting colony. After gently rocking the slide, the result is rapidly obvious, for the micro-organism is clumped by its corresponding serum very markedly, and not affected by any of the other sera. The result is easily read by the naked eye. By this means it is possible to label a case of acute diarrhnea as dysentery Flexner $\mathbf{Z}$ or dysentery Sonne, etc., within 18 hours of the onset of the diarrhœa. It is essential to have reliable sera. 
Secondly, more detailed examination of the micro-organism is usually required, although in very few cases have we come across disagreement between the ' rapid' and the more laborious methods. The colony to be investigated is picked off, grown in 1 per cent. peptone water for 6 hours, its motility examined, and then one or two drops of this culture are transferred to a series of carbohydrates for fermentation reactions. We use for routine purposes the following sugars:-Glucose, mannite, dulcite; lactose, saccharose, salicin, maltose, phenol red milk, and lactose gelatine. The Flexner sugar reactions, widely known, are normally the production of acid without gas formation in glucose, mannite, maltose and milk; the milk later turning alkaline. It is, of course, a non-motile gram-negative bacillus, and produces a variable amount of indol.

The reactions of the Sonne bacillus are less generally recognized. They consist of acid without gas formation in glucose, mannite, maltose, and milk, in 24 hours. Lactose is nearly always fermented, but this is a much slower process than with the other sugars, varying from 1 to 14 days. The milk remains acid throughout, and occasionally may be clotted. The reaction upon saccharose is variable, the sugar being sometimes fermented by Sonne and sometimes not. As a rule there is no production of indol, but an occasional indol-producer may be met.

Blood agglutination.-The majority of the cases of dysentery in these four years have been bled at least once, and their serum used for agglutination tests. Fifty control cases were also studied. Dreyer's method was used, and the antigens were Oxford standard agglutinable cultures, various stock strains of Sonne cultures, and when possible the patient's own culture. The results were of great interest, and we hope to make these, together with a full discussion on the bacteriology, the basis of a future paper. It will be sufficient here to say that we consider a ' standard' agglutination with any of the dysentery strains to a titre of $1 / 125$, or a strong agglutination even at 1/50, as presumptive evidence of a recent dysentery infection. We would also point out here the necessity of utilizing more than one strain of the Sonne bacillus for agglutinable cultures, as there is no doubt that many positive reactions are missed by not using representative mixed strains.

Symptomatology.-The clinical picture of the disease in most of the cases here recorded was abdominal pain followed by severe diarrhœa, usually associated with the passing of a fair amount of blood and mucus. The early dysenteric stool, in fact, is very typical, containing practically no fæcal material at all. There is a fair amount of tenesmus, and the child then passes a small quantity of blood and mucus. As many as six to ten motions may be passed during the day, and this diarrhœa is usually followed by constipation lasting one or two days. At the onset there is a good deal of molaise, irritability, sometimes vomiting, and in most cases a varying degree of temperature, $100^{\circ}$ to $103^{\circ}$, which symptoms may last only one day. Older children are rarely gravely affected, but whilst the diarrhœa lasts they may complain of thirst. In very young children the diarrhœa may be of a mild 
character, so much so that it may be considered unnecessary to make a bacteriological investigation or to regard the child as really at all seriously ill. All degrees of severity are met, however, from this mild type to the severest of all, when a young baby, usually under six months of age, is infected. The child passes blood and mucus six to eight times in one day, becomes rapidly dehydrated and collapsed, and may then die in a condition of severe toxæmia. The varying types that may be met have been well described by Paterson ${ }^{3}$ in the paper already referred to.

In some of the milder types, the associated abdominal pain, with the passage of blood and mucus has simulated very closely the picture of acute intussusception.

Treatment.-Taking general measures first, all patients must be treated as highly infectious, and should be nursed with most careful precautions to prevent spread. It is obvious that if a child passes as many as 10 stools in one day, and is handled by 3 or 4 nurses, the chances of spreading the infection are greatly multiplied. We would strongly urge that no nurse who is detailed to handle the stools of a dysentery patient be allowed to touch the food of any other patient. We are convinced that this is the most common mode of spreading the infection. The children have quite marked tenesmus, and but little control over these early very loose stools, and so the call for the bed pan should be quickly answered, or the bed clothes will have to be changed very often. They have very poor appetites during the acute stages, and will eat very little more than milk or pudding.

As regards medicinal treatment two modes of action may be adopted, either an attempt to clear the bowel of its noxious contents quickly by méans of aperients, or an endeavour to stop the diarrhœea, with its depleting effects, by means of bismuth. We have had no particular preference for either method of treatment, and cannot say that either gives better results than the other. The children appear to improve in any case.

Specific therapY.-(a) Bacteriophage. We have tried d'Herelle's dysentery-phage in the treatment of a few of the cases. This is prepared from a mixed culture, but does not contain any Sonne-phage. The results on the whole were disappointing, and as the children must be practically starved for 24 hours during the treatment, we no longer use it and do not feel justified in recommending its use.

(b) Serum therapy. Here, too, we have not had encouraging results. The most satisfactory of the sera appears to be the Lister antidysentery serum, which is mixed, and contains some Sonne antibodies. We feel bound to say in extenuation of these apparently unsatisfactory results of specific therapy, that they were not tried in the 1929 cases, and since then practically all the cases have been Sonne infections in older children, and have begun to show signs of recovery within 24 hours, before any particular treatment was adopted. If, however, a child is obviously acutely toxæmic, we would recommend the immediate administration of the serum, in doses of 10 c.cm. intramuscularly, repeated if necessary every 24 hours. 
TABLE 1.

SUMMaRY OF 106 CASES IN 4 Years.

\begin{tabular}{l|c|c|c}
\hline & Sonne & Flexner Z & Flexner W \\
\hline 1930 & $19+1$ nurse & $15+1$ nurse & 0 \\
1929 & 0 & 1 & 0 \\
1931 & $25+1$ nurse & 1 & 1 \\
1932 (11 months) & $38+3$ nurses & 0 & 0 \\
\hline \multicolumn{1}{c|}{ Totai } & $82+5$ nurses & $17+1$ nurse & 1 \\
\hline
\end{tabular}

Incidence.-It will be seen in Table 1 how the incidence of dysentery varies in this hospital. Of a total of 106 cases of dysentery over a period of 4 years, there were 18 cases of Flexner Z, and 16 of these occurred in 1929. Sonne infections are more evenly spread, except in 1930, when there was not even one case. All these cases were bacteriologically proven by isolating the micro-organisms from the stools. There were several cases of undoubted dysentery, not bacteriologically proven and therefore omitted from this paper, which were the obvious starting point of an epidemic, and the agglutination reactions of their blood proved to our satisfaction the true nature of their infection.

A severe ward outbreak at the end of 1928 induced us to investigate fully every case of diarrhœa occurring in the hospital. Until that time the importance of the immediate bacteriological examination of all abnormal stools, particularly those showing blood and mucus, was not recognized in the wards. We give here a short summary of the worst of the epidemics of 1929 .

1. The first cases investigated were the members of one family. In this family a boy, aged 1 year and 11 months, was taken ill with acute diarrhœa at a convalescent home early in January, 1929. On the 17th he returned home, and within 3 days, 4 other members of the family became severely ill with acute diarrhœa, the eldest, aged 8 years, dying within 14 hours of the onset of the diarrhœa. Two of the children came into hospital, and made good recoveries. Flexner $\mathrm{Z}$ was the causal micro-organism, and it was recovered from the stools of the first case and from one of the brothers. A coroner's inquest was held on the child that died, and a verdict of death from 'acute food poisoning' was returned, because there was no bacteriological examination made of the bowel. In March, Flexner $\mathrm{Z}$ was still isolated from the stools of the original case, and his blood agglutinated Oxford $\mathrm{V}$ and $\mathrm{Z}$, but stronger with $\mathrm{Z}$.

2. (Medical Ward A.) L. N., aged 1 year and 2 months, had erysipelas of the thigh for which he was admitted to another hospital. He had slight diarrhœa when admitted there just before Christmas, 1928. On the 17th January, 1929, he was admitted into this hospital markedly collapsed (temperature $96^{\circ}$ ), and he had 1 stool that day. Next day his temperature rose to $100^{\circ}$ and he passed 9 stools which were green, with some blood and mucus. He went on passing 7 to 10 stools per day until his death on the 23rd January. None of these stools was examined bacteriologically. At the post-mortem examination the bowel was 'flannel-like' and injected, but there was no true ulceration and no dysentery bacilli were isolated from the inflamed areas. The heart's blood agglutinated well with Oxford Flexner Z and Sonne.

Following this, on the 20th January, 1929, another child aged 6 weeks, who had been in hospital since the 15th December, 1928, for vomiting, and had made a good recovery, developed an acute diarrhœa, with a temperature of $102^{\circ}$. Eight stools were passed that day, and thereafter an average of 7 stools per day until death on 29th January. The temperature chart in this case was of interest, there 
being a slow daily decline from $102 \cdot 4^{\circ}$ on the 22nd January to $95^{\circ}$ on the 28 th, the day before death. Flexner $\mathrm{Z}$ was isolated from the stools in this case during life, but the bowel, post mortem, although showing typical dysenteric lesions, yielded no dysentery organisms on culture.

On the 22nd January, 1929, a nurse who had had charge of both these cases was taken ill with acute diarrhœa and Flexner $Z$ was isolated repeatedly from her stools. Her blood on the 29th January agglutinated well with the dysentery bacilli but best with Flexner $\mathrm{Z}$.

3. (Surgical Ward A.) S. H., aged 6 months, was admitted on January 17th, 1929, with blood and mucus in his stools under the diagnosis of recurrent intussusception. During the previous 2 days he had been passing a slight amount of blood and mucus. On admission the child showed no physical signs and the stools were normal. On 23rd the temperature began to rise, reaching $102^{\circ}$ on the 27 th. The stools simultaneously increased to 3-5 per day, and the child died on February 7th with a temperature of $103^{\circ}$. No stools were sent for investigation during life, and post mortem no obvious dysenteric lesions were detected, and as dysentery was not suspected no bacteriological examination was made.

Following this case between the 6th and 20th February 6 other children, the majority of whom had been in hospital for some time, suddenly developed acute diarrhœe of a severe type. Three of these children were under 2 years of age and died; 1 aged 3 and the other 2 aged 10 recovered. B. Sonne was isolated from each of these cases: in the 3 that recovered it was found in the fæces; in 2 of those that died it was found in post-mortem lesions of the bowels; and in the third of the fatal cases it was recovered from the fæces during life but not from the bowel post mortem.

4. (Surgical Ward B.) A. H., aged $7 \frac{1}{2}$ years was admitted on October 5th, 1929, for tonsillectomy. She had slight pyrexia $100^{\circ}$ and loose motions on admission. On the 6th she had 3 watery stools with blood and mucus, but notwithstanding this she was allowed up and played with other children in the ward. On the 7th B. Sonne was isolated from her stools. Her temperature was normal throughout and the patient became a convalescent carrier, the micro-organisms being isolated over a month later.

In connection with this case 3 children in the ward developed diarrhœa with blood and mucus, and from each one the Sonne bacillus was isolated. All made uninterrupted recoveries.

5. (Medical Ward B.) M. W., aged 3 years, was admitted for pains in the stomach, vomiting and severe diarrhœa with a good deal of blood and mucus. This had started on the 3rd October, and she was admitted on the 4th with a temperature of $101^{\circ}$. She passed 10 stools on the first day, then $6,5,4$ and 1 on consecutive days. Flexner $\mathrm{Z}$ was isolated from the stools, and anti-dysenteric serum was given in $10 \mathrm{c} . \mathrm{cm}$. doses daily for 4 days. The temperature was normal by the 9th, and the patient was discharged as fit on the 16th October.

Following on this case there were 5 cases of dysentery in this ward. The first of these cases started on the 27th October, i.e., eleven days after the child M. W. had been discharged, and the last one to occur was in a child aged 4 months, who had been admitted for feeding difficulties and anæmia, and who had been doing well until he started an acute diarrhœa on the 12th November, from which he died on the 20th. In all these cases Flexner $\mathrm{Z}$ was isolated from the stools.

In the later years early examination of suspected stools has often put us on guard against the spread of infection, but even so we have had many small epidemics, usually affecting 4 to 8 children in one ward before it is properly stamped out. The earlier recognition of cases has, however, diminished the number of contact cases as, for example, in one ward where 4 cases of dysentery were admitted in 1932 and there followed only 1 contact case. 
TABLE 2.

Age and Mortality incidences.

\begin{tabular}{|c|c|c|c|c|c|c|c|c|c|}
\hline & & \multicolumn{2}{|c|}{1929} & \multicolumn{2}{|c|}{1930} & \multicolumn{2}{|c|}{1931} & \multicolumn{2}{|c|}{1932 (11 mo.) } \\
\hline & & Flexner & Sonne & Flexner & Sonne & Flexner & Sonne & Flexner & Sonne \\
\hline Under 1 year & $\ldots$ & $3(2)$ & $4(3)$ & 0 & 0 & 0 & 1 & 0 & 1 \\
\hline 1-2 years ... & $\ldots$ & 4 & 2 (1) & 0 & 0 & 0 & 1 & 0 & 10 \\
\hline $2-5$ years $\ldots$ & $\ldots$ & 4 & 5 & 0 & 0 & 0 & 10 & 0 & 10 \\
\hline $5-12$ years & $\ldots$ & 4 & 8 & $1 \mathrm{z}$ & 0 & $1 z-1 w$ & 14 & 0 & 17 \\
\hline Nurses & $\ldots$ & 1 & 1 & 0 & 0 & 0 & 1 & 0 & 3 \\
\hline Totals & $\ldots$ & $\left|\begin{array}{ll}16 & (2)\end{array}\right|$ & $20(4)$ & 1 & 0 & 2 & 27 & 0 & 41 \\
\hline
\end{tabular}

The numbers of fatal cases are given in brackets.

Age and mortality incidences.-From Table 2 it can be seen that all the deaths occurred in 1929. All of these were under 2 years of age, and of the total of 6 fatal cases, 4 were from Sonne and 2 were from Flexner $\mathrm{Z}$ infections. The total death rate over the 4 years, however, is very much more favourable in Sonne infections, being only 4 out of 88 cases (4.5 per cent.), whereas with Flexner infections there were 2 deaths out of 19 casesreally too few from which to draw conclusions, but nevertheless giving a death rate of 10.5 per cent., or more than double the Sonne rate.

The mode of infection is important from the statistical point of view. In 1929 there were 15 cases infected outside the hospital, and these gave rise to 21 cases after admission. In 1930 the only case of the year was admitted for its dysentery. In 1931, of the 29 cases, 11 were admitted, and 18 contracted in hospital. 1932 shows 13 cases admitted, giving rise to 28 cases contracting dysentery in hospital.

\section{Discussion.}

The object of this paper is to draw the attention of pædiatricians to the frequent occurrence of bacteriological dysentery in institutions in which children are cared for. Our experience in this hospital is almosĩ certainly not unique, for we know that several children's hospitals in London ${ }^{4}$ and the provinces ${ }^{5,6,7}$, have similar outbreaks. Reports from various Continental countries ${ }^{8,9}$, Australia ${ }^{10}$, Canada ${ }^{11,12}$, India ${ }^{13}$, and the United States of America ${ }^{14}$ show also that similar outbreaks of dysentery occur in those countries.

Our investigations lead us to conclude that the commonest infecting micro-organism is the Sonne bacillus, and we may add that we very rarely indeed come across Morgan's No. 1 bacillus, which for some years was regarded as a likely cause of epidemic diarrhœa. Even to this day the Sonne bacillus is by most clinicians and pædiatricians regarded as of little practical importance, but it should be recognized that in very young children it may produce fatal infections. The ultimate effects of the dysentery bacillus are not known, but it is possible that cases of arthritis, malnutrition and even cœliac disease may be numbered amongst them, and the positive blood agglutinations which have sometimes been found associated with these 
clinical conditions, may indicate that the disease may be an ætiological factor.

Several of our cases have become convalescent carriers, harbouring the micro-organism for months after the attack, without apparently any ill effects after the first symptoms had subsided. They are the probable sources of infection in most outbreaks. The infection spreads rapidly amongst children living together, and too great stress cannot be laid upon the adoption of stringent precautions to prevent this spread.

Treatment in these cases is rather unsatisfactory, because it is apparently unnecessary to interfere in most of them. Nevertheless, with the ordinary means of treatment employed, relapses sometimes occur, and it is quite possible that treatment with anti-dysenteric serum in a severe case might prevent such relapses. It certainly holds out the greatest hope in the case of an infant who is severely affected, if administered together with bismuth to combat the diarrhœa.

\section{Summary.}

1. The incidence of dysentery from the Flexner and Sonne bacilli is given in a children's hospital, over a period of 4 years, totalling 106 cases.

2. Deaths are recorded in 4.5 per cent. of Sonne infections and 10.5 per cent. of Flexner infections; but in the majority of cases, particularly in older children, the disease is mild.

3. The bacteriology of the fæces and the blood agglutinations are briefly discussed, and the importance of the latter emphasized.

4. Suggestions are put forward for minimizing the risk of spread in institutions.

We wish to thank the Honorary Staff of the hospital for permission to use the material under their care.

\section{REFERENGES.}

1. Distaso, A., \& Nabarro, D., C. R. Soc. Biol., Paris, 1914, LXXVI, 577.

2. Duval, C. W., \& Bassett, V. H., Bact. \& Clin. Studies of the Diarrhoeal Dis. of Inf., Rockefeller Inst. Med. Res., N.Y., 1904.

3. Paterson, D., \& Nabarro, D., Lancet, Lond., 1922, ii, 320; Brit. Med. J., Lond., 1923, ii, 857; J. Path, \& Bact., Edinb., 1923, XXVI, 429.

4. Mansell, H. E., Lancet, Lond., 1930, i, 1181.

5. Cruickshank, R., Quart. J. Med., Oxford, 1925, XVIII, 339.

6. Wiseman, W. R., J. Hygiene, Camb., 1927, XXVI, 187.

7. Clayton, F. H. A., \& Hunter, J. W., Lancet, Lond., 1928, ii, 649.

8. Sonne, C., Centr. f. Bakter., I Orig., Jena, 1915, LXXV, 408; 1915, LXXVI, 65.

9. Torres-Umana, C., Rév. Franc. de pédiatr., Paris, 1926, II, 407.

10. Little, M., Med. J. Austral., Sydney, 1923, II, 645.

11. Johnston, M. M., Brown, A., \& Tisdall, F. F., Can. Med. Ass. J., Toronto, 1930. XXIII, 231.

12. Johnston, M. M., \& Brown, A., Can. Pub. Health J., Toronto, 1930, 395; Can. Med. Ass. J., Toronto, 1931, XXIV, 364.

13. Ukil, A. C., \& Sen, A. K., Calcutta Med. J., Calcutta, 1927, XXI, 573.

14. Nelson, R. L., Am. J. Child. Dis., Chicago, 1931, XLI, 15. 